\title{
The course of depression following myocardial infarction and the impact of the social neglect on the recovery of the patient
}

\begin{abstract}
Introduction: A number of studies have demonstrated a relationship between depression and low perceived social support and increased cardiac morbidity and mortality in patients with coronary heart disease. Depression increases the length of hospitalization, diagnostic procedures and the medical care cost.

Case report: A 49 years old married male, unemployed construction technician, war veteran, suffered two episodes of depression after acute myocardial infarction (AMI). The first episode appeared one month after MI following the mistreatment by his employer. His employer dismissed him after he returned to his working place when he finished his sick leave. The second episode occurred with suicidal ideas and culminated with the attempt of suicide. He had individual Eye Movement Desensitization and Reprocessing (EMDR) psychotherapy, group psychotherapy with other war veterans and psycho-pharmacotherapy. He dismissed as recovered and stabilized on outpatient treatment and referred on Institution for Pension and Invalidity for assessment of remained working capacity.
\end{abstract}

\begin{abstract}
Discussion: High levels of social support predict improvements in depression symptoms over the first post-MI year in depressed patients. High levels of support may protect patients from the negative prognostic consequences of depression because of improvements in depression symptoms. To ensure that patients after AMI are able to return to previous levels of functioning, it is important to provide adequate health care, both in somatic and psychiatric aspects of treatment, as well as appropriate social support from the community, including the employment management.
\end{abstract}

Conclusion: Due to social neglect by his employer in the time of recovery from acute MI, the patient suffered from two severe episodes of depression which had negative impact on his recovery. It is crucial for physicians to have an integrative and holistic, patient oriented approach in the treating of somatic diseases and include adequate psychological evaluation of the patients as well as the active participation of social community in the healing process.
Volume 6 Issue 6 - 2017

\author{
Mevludin Hasanović, ${ }^{1,2}$ Amila Čizmić,' \\ Miralem Jašarević \\ 'School of Medicine, University of Tuzla, Bosnia and Herzegovina \\ ${ }^{2}$ Department of Psychiatry, University of Tuzla, Bosnia and \\ Herzegovina
}

Correspondence: Mevludin Hasanović, Department of Psychiatry, University Clinical Center Tuzla Ul. Rsate Dugonjića bb, 75 Tuzla, Bosnia and Herzegovina, Tel 0038761656 608, Email hameaz@bih.net.ba

Received: April 14, 2017| Published: May 30, 2017

Keywords: depression, acute myocardial infarction, social neglect, suicidality, job loss, retirement

\section{Introduction}

Depression and low perceived social support (LPSS) after myocardial infarction (MI) are associated with higher morbidity and mortality. In the original AHRQ EPC report, prevalence varied by type of measure used. For example, use of the Structured Clinical Interview for the Diagnostic and Statistical Manual (SCID) yielded prevalence ranging from $17 \%$ to $27 \%$. Including the ENRICHD trial at $20 \%$ and validated depression scales, such as the Beck Depression Inventory (BDI), yielded prevalence ranging from $10 \%$ to $47 \%$, depending on the cut points used. The updated evidence review continued to show a wide range of prevalence $(7.2 \%$ to $41.2 \%)$ depending on the method used to assess depression. Structured interviews tended to produce lower prevalence estimates, and ratings scales, such as the BDI, produced higher prevalence estimates. In general, across the studies, about 1 of every 5 patients with an MI has depression during an initial hospitalization. ${ }^{1}$

Depression is an independent risk factor for increased postmyocardial infarction morbidity and mortality, even after controlling for the extent of coronary artery disease, infarct size, and the severity of left ventricular dysfunction. This risk factor takes on added significance when one considers that almost half of patients recovering from a myocardial infarction have major or minor depression and that major depression alone occurs in about one in five of these individuals.
Despite the well-documented risk of depression, questions remain about the mechanism of the relationship between mood disturbance and adverse outcome. The link may be explained by an association with lower levels of social support, poor adherence to recommended medical therapy and lifestyle changes intended to reduce the risk of subsequent cardiac events, etc., ${ }^{2}$

The symptoms of depression can be complex and vary widely between people. But as a general rule, patients feel sad, hopeless and lose interest in things they used to enjoy. The symptoms persist for weeks or months and are bad enough to interfere with patient's work, social life and family life. Depression is not a normal part of growing older and it should never be taken lightly. Unfortunately, depression often goes undiagnosed and untreated in older adults, and they may feel reluctant to seek help.

\section{Case report}

On July $6^{\text {th }} 2012$, a forty-six years old male, a construction technician, had a myocardial infarction late at night while filling out the construction diary at home. He felt sudden, severe, piercing pain in his left fist, which extended through left forearm, upper arm, back and left side of the chest. With his wife he went to the Emergency Department where he was diagnosed with AMI based on his ECG recording. He was directed to the Department of Internal Medicine 
where he was examined and treated for his somatic condition. He was hospitalized for one month and after he had a carotid artery stenting surgery. During sick leave and after the surgery no one has called him from work or visited him in hospital. One month after surgery he showed up at his work where the director of the construction company told him he no longer needed him, he found him no longer fit for this or any other job in company, he cannot take care of him, he is not his father. Patient was shocked, he protested and at that moment there was a verbal confrontation between the director and him. When he came home, he was tense, could not sleep, he was irritable and argued with family members. In December 2012 his wife went to his working place for him to ask the director to certify his health card. She was verbally attacked and forced out from the company. The patient was in the car and saw her been thrown out. He rushed into the company, smashed two computers and demolished the management room. He was looking for the director of the company with the intention to kill him. Because of that he was prosecuted and the court granted him one month of probation due to the health circumstances and the fact he pleaded guilty. Next day he went to neuropsychiatrist because he had suffocation attacks, sleeping issues, he was tense, irritable and fractious. The recommended therapy helped a bit, he felt better and continued to come for control examinations.

Due to the suffocation attacks he was hospitalized several times at the Clinic for Internal Medicine where he did coronary angiography which revealed existence of two-vessel coronary artery disease. Due to the deterioration of his mental state in the form of chest discomfort, restlessness, insomnia, nightmares, fear of death, stiffness when walking, with aches in the neck part of the spine with expansion in the right arm, he was hospitalized at the Psychiatry Department on November $3^{\text {rd }} 2013$. His psychological status states that the patient was tense and anxious, with low threshold for frustrations, low basic mood and slow thinking process. In his thought content were depressive ideas, ideas of hopelessness and lack of perspective. One had the impression of PTSD symptoms in term of reliving and increased arousal. At this time patient was on sick leave for about a year.

Patient is second of four children. His father died when he was 13 after that he felt an intense fear of staying alone at home. He described his mother as a rigorous woman. He was too attached to his mother and had a hard time when she died after suffering leukemia. He was an excellent student and a basketball player. He finished high school and went to the then obligatory military service where he was an exemplary soldier. After military service 1987 he got his first job at a construction company as a construction technician where he worked until nine years ago, when the company has been shut down. From that period until the myocardial infarction he worked for another construction company which he helped develops. He was very satisfied with his working conditions until a year before myocardial infarction. At that period of time he noticed the director of the company changed his attitude towards him. He became cold and distant and started to supervise him and to send others to do supervision for him. He noted the sabotages on his working place as well as withholding the funds necessary for construction. Then he started having insomnias and chest discomfort. He was working hard and trying to finish the work on the construction site before deadline which he succeeded but he had to work overtime and often at home as well.

During the hospitalization, patient's history of war experience in duration of four years was established, in which he had witnessed death of fellow soldiers, saw their dismembered body parts and has been injured twice. He has also mentioned losing consciousness twice during shell's detonations. He often has nightmares about war events, nearly every second night. He has been at the Clinic for Lung Diseases due to sleep apnea. Patient's condition was stabilized and he was discharged on November 28th 2013 with following diagnoses: F 33.3Recurrent depressive disorder, F 07.2- Postconcussional syndrome, F62.0-, PTSD- complex form, Z 65.5- Exposure to disaster, crime and other hostilities, i.e. the experience of the war disaster, the experience of the death and wounding of comrades, experience the treatment of a serious illness, the experience of his father's death in early childhood, the experience of the mother's death after a serious illness; Status Post infarctus myocardii, Two-vessel coronary heart disease, Hypertension arterial, and an ENT specialist diagnosed him with Hypoacusis perceptive bilateralis, Tinnitus bilateralis.

The second hospitalization occurred on February $12^{\text {th }} 2015$ because of severe episode of depression with suicidal ideas. Patient stated that he wanted to kill himself; he fantasized cutting himself with a knife. He planned the place and time of suicide and the way of doing it. While doing that he felt pleasure and then he fell asleep. He saw suicide as the only way out from his situation. He is now unemployed, and is trying to get the invalidity pension with no success yet. His family and he are living on his wife's salary. He feels incapable of doing any kind of work and is convinced that none of this would have happened if he had started to work in his previous company when he was recovered from infarction and operation. During the examination patient had increased tenacity for rumination of negative thoughts, preoccupation with somatic complaints with features of hypochondria. He was in fearful anticipation and had suicidal impulsions, feeling of hopelessness, and loss of perspective and foreshortened future. He was anxious and agitated occasionally up to psychotic level.

Laboratory findings showed elevated level of triglycerides, AST, ALT. He had high blood pressure and has been taking therapy for it. During hospitalization he suffered from a jaw infection which later affected the pharynx. He was ordained with antibiotics and was better. He still had trouble sleeping and on one occasion had behaved violently. During the inpatient treatment he had individual Eye Movement Desensitization and Reprocessing (EMDR) psychotherapy and group psychotherapy together with other war veterans together with psycho-pharmacotherapy: Diazepam, Clozapine, Venlafaxine, Carbamazepine; and Lisinopril, Nebivolol, Aspirin, and Acetaminophen. He dismissed as recovered and stabilized on outpatient treatment with recommendation to be referred on Institution for Pension and Invalidity for assessment of remained working capacity. The current condition of the patient can be considered definitive. More significant recovery is not expected by further treatment.

\section{Epilogue}

Patient is now forty-nine years old, unemployed and unfit to work. $\mathrm{He}$ is trying to get an early retirement but with skeptical chances of success due to the lack of regulations and ethics which is possible in a transitional country, such as Bosnia and Herzegovina. The destiny of this patient is very questionable in perspective because of lack of knowledge and ethics in industry management who do not take adequate care of their workers who survive life threatening medical conditions.

\section{Discussion}

After the war in Bosnia-Herzegovina, mental illness is very prevalent. ${ }^{3,4}$ With little knowledge about mental health, the stigma of mental illness is still pervasive in many communities. ${ }^{5}$ After AMI the most important is to begin emergency treatment within the so-called "golden hour" following the injury. Work stress is associated with an increased risk for cardiovascular disease (CVD) ${ }^{6}$ Over commitment 
to work is associated with an increase in basal sympathetic drive and a reduction in the dynamic range of cardiac sympathetic regulation. Prospective studies have shown that effort-reward imbalance (ERI) at work is associated with the incidence of a first coronary heart disease (CHD) event. ${ }^{7}$ Myocardial infarction is an example of a sudden, potentially shocking and life-endangering event, which may profoundly alter life-style and future expectations. Depressive and anxiety reactions are the most commonly described psychic reactions following MI. Depressive symptoms are reported in the range of 2050 percent. ${ }^{8}$ Depression is a common condition in patients with acute MI, affecting approximately $20 \%$ of patients during hospitalization and a similar proportion at some point during the first year after MI. Depressive symptoms, even in the absence of formal diagnosis of major depression, is strong independent predictors of morbidity and mortality after MI. ${ }^{9}$ Data suggest that there may be two types of depression following MI: an acute depression associated with greater functional impairment, and a prolonged depression that may be associated with inadequate social support. ${ }^{6}$ Post-MI depression is an independent risk factor for increased mortality. ${ }^{10}$

Through identification and reduction of barriers to following behavioral recommendations, including the presence of negative mood states and other psychological factors, physicians should help provide patients with external support systems such as referral to support groups or telephone follow ups, when necessary. Such external supports, however, often require other approaches for longterm maintenance of new health behaviors. A motivational literature suggests that physicians can promote patient self-management by formulating health goals in a manner that satisfies "basic psychological needs" such as the needs for autonomy and competency. ${ }^{11}$

The health determinant, social isolation or lack of a social support network (SSN), and their effects on premature mortality after acute MI may mandate further scrutiny by the cardiovascular community, for several reasons. First, as a predictor of 1-year mortality, a low SSN is equivalent to many of the classic risk factors, such as elevated cholesterol level, tobacco use, and hypertension. Therefore, the absence of social supports should be considered a risk factor for complications after MI. In fact, many of the biochemical markers that mediate the effects of elevated cholesterol level or tobacco use are also elevated in the depressed individual. Second, treatment of acute MI is costly. Because low social support is associated with increased 1-year mortality, neglecting the role of the SSN may diminish the possible gains accrued during acute-phase treatment. ${ }^{12}$

High levels of social support predict improvements in depression symptoms over the first post-MI year in depressed patients. High levels of support may protect patients from the negative prognostic consequences of depression because of improvements in depression symptoms. ${ }^{13}$ To ensure that patients after AMI are able to return to previous levels of functioning, it is important to provide adequate health care, both in somatic and psychiatric aspects of treatment, as well as appropriate social support from the community, including the employment management.

\section{Conclusion}

Inadequate relationship between an employer and an employee could lead to an increased risk of acute coronary artery disease as a result of stress at work, excessive overtime and over commitment to work without consequential awards. Depression can occur after an acute myocardial infarction and, consequently, has a significant impact on morbidity of somatic disease. Patients in the post infarct-period are difficult to recover from depression due to the lack of adequate social support from the community. This can result in the progression of depressive symptoms in the form of occurrence of suicidal ideation and suicide attempts, increased risk of subsequent heart incident and permanent or temporary disability and inability to work. Lack of understanding by the employer of the employee, who suffered severe somatic disease, such as myocardial infarction, is an important social factor in the recovery of somatic diseases and the emergence of mental disorders that accompany it. Patients who survived after acute myocardial infarction need occupational rehabilitation and resocialization, as well as adequate social support from the employer and the community, in order to prevent mental illness or, if it has already develop, to reduce the intensity of symptoms and prevent its deterioration.

\section{Acknowledgments}

None.

\section{Conflicts of interest}

None.

\section{Funding}

None.

\section{References}

1. Post-Myocardial Infarction Depression Clinical Practice Guideline Panel. AAFP guideline for the detection and management of postmyocardial infarction depression. Ann Fam Med. 2009;7(1):71-79.

2. Ziegelstein RC. Depression after myocardial infarction. Cardiol Rev. 2001;9(1):45-51.

3. Avdibegovic E, Hasanovic M, Selimbasic Z, et al. Mental health care of psychotraumatized persons in post-war Bosnia and Herzegovina-experiences from Tuzla Canton. Psychiatr Danub. 2008;20(4):474-484.

4. Hasanovic M, Herenda S. Post traumatic stress disorder, depression and anxiety among family medicine residents after 1992- 95 war in Bosnia and Herzegovina. Psychiatr Danub. 2008;20(3):277-285.

5. Hasanovic M, Sinanovic O, Pajevic I, et al. Post-war mental health promotion in Bosnia-Herzegovina. Psychiatr Danub. 2006;18(1-2):74-78.

6. Travella JI, Forrester AW, Schultz SK, et al. Depression following myocardial infarction: a one year longitudinal study. Int J Psychiatry Med. 1994;24(4):357-369.

7. Vrijkotte TG, van Doornen LJ, de Geus EJ. Overcommitment to work is associated with changes in cardiac sympathetic regulation. Psychosom Med. 2004;66(5):656-663.

8. Aboa-Éboulé C, Brisson C, Maunsell E, et al. Effort-reward imbalance at work and recurrent coronary heart disease events: a 4-year prospective study of post-myocardial infarction patients. Psychosom Med. 2011;73(6):436-447.

9. Parashar S, Rumsfeld JS, Spertus JA, et al. Time course of depression and outcome of myocardial infarction. Arch Intern Med. 2006;166(18):2035-2043.

10. Ziegelstein RC. Depression in patients recovering from a myocardial infarction. JAMA. 2001; 286(13):1621-1627.

11. Rozanski A. Integrating psychologic approaches into the behavioral management of cardiac patients. Psychosom Med. 2005;67 Suppl 1:S67-S73.

12. House JS. Social isolation kills, but how and why? Psychosom Med. $2001 ; 63(2): 273-274$.

13. Frasure-Smith N, Lespérance F, Gravel G, et al. Social support, depression, and mortality during the first year after myocardial infarction. Circulation. 2000;101(16):1919-1924. 